\title{
ASSET MANAGEMENT IN GRID COMPANIES USING INTEGRATED DIAGNOSTIC DEVICES
}

\author{
L. D. GITELMAN ${ }^{1}$, M. V. KOZHEVNIKOV ${ }^{1} \&$ D. D. KAPLIN ${ }^{2}$ \\ ${ }^{1}$ Department of Energy and Industrial Management Systems, Ural Federal University, Russia. \\ 2 JSC "Rosseti Ural", Russia.
}

\begin{abstract}
The digitization of power grids envisages a transition to new models of fault diagnosis, repair and maintenance of electric power grid equipment. The most promising tools for implementing advanced production asset management strategies are integrated technologies that are based on robotic diagnostic platforms, various hardware-software instruments and smart data analysis systems. The article analyzes other countries' experience of developing robotic methods of fault diagnosis and maintenance of overhead power transmission lines, which present a major challenge in terms of monitoring, failure prediction and localized repairs. The Cablewalker robotic system was used as an example for identifying the advantages of integrated diagnostic hardware systems as opposed to traditional methods of power grid equipment maintenance and overhaul. Recommendations are given for adopting the technology in grid companies. During trials of the technology on a 2.34-km section of a power transmission line 112 defects were detected versus three that were identified by means of 'manual' inspection. A digital twin of the transmission line was created to manage its technical condition with regard to various risks.

Keywords: asset management, robotic diagnosis, grids, overhead transmission lines, maintenance strategies, digital twin.
\end{abstract}

\section{INTRODUCTION}

A digital transformation that is taking place in the electrical power industry of many countries is usually shaped by region-specific tariff and balance constraints. This means that digitization programs have to be recouped by energy companies through cost reallocation [1-4].

International experience shows that the digital transformation of grids results in lower power losses, higher reliability and accessibility of power supply and creates a number of additional services for customers [5-7]. The adoption of digital technologies entails savings in the course of the implementation of investment programs and opens up opportunities for the accelerated expansion of power distribution infrastructure, ensuring higher profitability of the energy business and reducing SAIDI/SAIFI and preparing energy companies for new technological challenges [8-11].

A technological overhaul of the grid infrastructure is impossible without changing the production asset management system and rethinking approaches to repairs and maintenance. Overhead transmission lines (OTL) (especially medium- and high-voltage ones) are one of the most difficult pieces of equipment to repair and maintain. Faults in overhead transmission lines lead to major disruptions in grid operation. Faults in OTLs typically occur because:

- transmission line design does not fit local climate conditions as OTL design requirements have not been fully taken into account;

- there are defects in conductors, cables and insulators;

- unsatisfactory condition of power line routes and components;

- defects in pylons, foundations and connectors [11-13]. 
Today, many countries have to urgently address the issue of the timely detection and elimination of defects in transmission lines [14-17]. What makes it highly relevant to design appropriate 'preemptive' solutions is their strong economic effect that shows in lower expenditures on the elimination of failures, compensation of power losses and operating costs $[13,17-20]$.

Until recently, the task was addressed by shutting off the equipment and conducting manual visual inspection. The method implies that transmission lines are de-energized and power supply is cut off to consumers. This makes the method unproductive and constitutes an obvious disadvantage.

All too often, effective monitoring of $35-\mathrm{kV}$ and higher transmission lines becomes even more challenging because they are long and inaccessible to ground vehicles. This is particularly relevant to vast countries and countries with complex terrain (Russia, Canada, Italy and others). An alternative is to use piloted aircraft or unmanned robots to monitor such facilities [20-22]. This study analyzes the capabilities of diagnostic and maintenance robots for overhead transmission lines, including the Russian-made Cablewalker technology that is now in trial operation.

The research method included several stages. As part of stage one, the available literature was analyzed to identify and classify the main approaches to grid asset management; their respective advantages and disadvantages and application limits. During stage two, a comparative analysis was performed of existing robotic solutions for OTL inspection; components of integrated diagnostic hardware tools were described and grid asset management assignments for such tools were identified. At stage three, the results of the trials of the Cablewalker platform were analyzed and the technical and economic efficiency of the technology adoption by Russia's biggest grid company Rosseti Ural was assessed. The assessment examined three scenarios over the ten-year horizon. Trials of the platform in Russia, the UAE, and Vietnam that have taken place over the past five years as well as the pilot run of the platform on a $220-\mathrm{kV}$ transmission line including the creation of a digital twin in August 2018 served as the empirical base of the study.

\section{MAIN APPROACHES TO GRID ASSET MANAGEMENT}

Strategies for grid asset management can be grouped according to costs of carrying out maintenance and repairs, operational availability of equipment, and the ratio of manual vs automated methods of repair [23, 24]. The most typical classification of management strategies distinguishes whether the condition of the component is considered on the one side and whether the importance of the component is considered on the other side (Fig. 1). Both the condition and the importance of components can be defined in many ways, depending on the desired level of detail and the availability of appropriate data. For example, the definition of importance may be oriented at quite simple aspects like the number of feeders of a substation, or at more sophisticated indices like the share of the energy not supplied in time caused by failure of each respective component.

The most simple maintenance strategy according to this classification is the so-called Corrective Maintenance that does not actually imply any preventive maintenance at all - the component is operated until it fails. Then it is decided whether the component can be repaired or whether it must be replaced. This strategy is fraught with high costs as it significantly derogates supply reliability, thus creating the risk of causing additional economic consequences for the network operator. It makes it possible to utilize the full potential of the component, but may result to frequent and prolonged shutdowns, posing a risk of substantial 


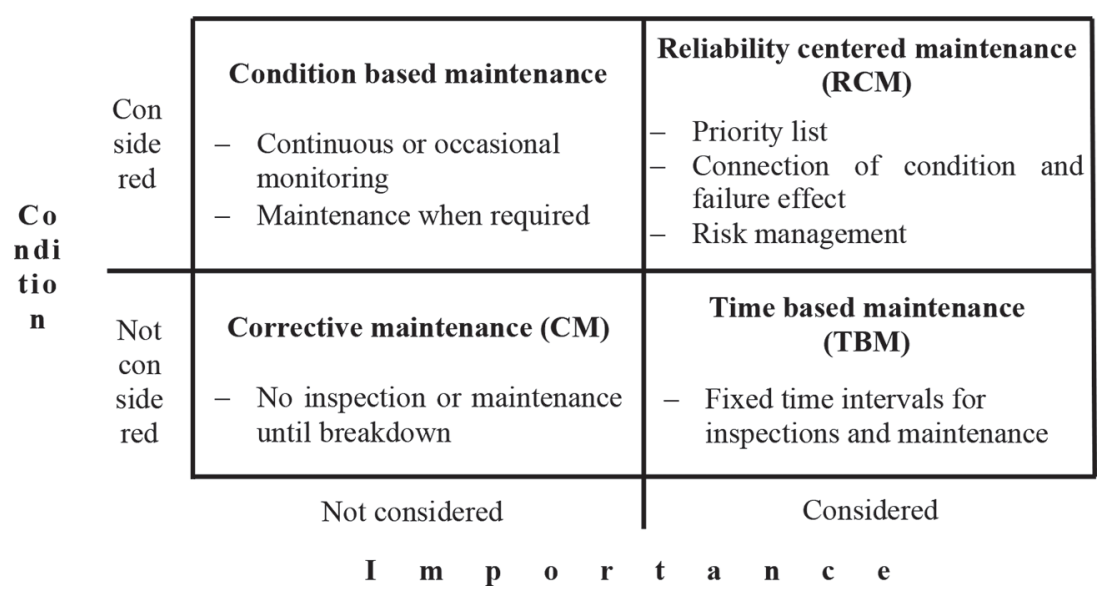

Figure 1: Classification of maintenance strategies.

damage and expenses on emergency repairs. Corrective maintenance is therefore suitable when the component is non-critical and consequences of a failure are not serious. In distribution networks, the method is widely used for MV-XLPE cables where preventive maintenance is not an option, and at the low-voltage level [25].

Time-based maintenance means there are fixed time intervals for inspections that are given either by the manufacturer of the equipment or the network operator. The method is appropriate for those instances when an abrasive, corrosive wearout takes place, or material properties change due to fatigue. The strategy is widely used in maintenance of high-voltage and medium-voltage networks as it combines and acceptable availability with comparably high costs.

Condition based maintenance is mainly used in high-voltage and extra high-voltage grids, but some utilities are trying to adopt this strategy for the medium-voltage level, too. Under this strategy, maintenance activity is triggered by the component condition reaching certain thresholds. Condition based maintenance leads to high availability and moderate maintenance costs.

In practice, though, financial and logistical limitations necessitate additional priority setting. For example, extra high-voltage grids, the focus is on system integrity, scheduling of power plants and prevention of bottlenecks in transmission capacity. As the most advanced asset management strategy, reliability centered maintenance not only considers the condition of single units (the system components), but also takes into account the impact on the performance of the system.

The third and fourth strategies rely on methods and means of integrated tool-assisted diagnosis that make it possible to determine the status of equipment through continuous or discrete control over parameters affecting its performance. When the component condition parameters reach certain thresholds (in terms of reliability), preventive interventions are performed. The strategy proves effective in application to complex equipment that is expensive to repair. The method enables utilities to fuller utilize their technical resources and ensure reliable operation of equipment while keeping costs at a minimum.

The above approach to choosing an asset management strategy not only helps evaluate the priorities for maintenance actions but is also a powerful tool for the ranking of replacement and refurbishment activities, because bad equipment conditions lead immediately to the 
question whether it is more economical to do further maintenance or replace the equipment. This analysis can be done for the single piece of equipment as well as for complete facilities (e.g. substation) where a combination of the conditions of different parts (concrete and steel, primary and secondary equipment) is regarded [26, 27].

It is obvious that in order to adopt advanced asset management strategies, it is necessary to have modern grid monitoring systems that are capable of performing the diagnosis of and forecasting failures and, ideally, carrying out localized repairs, reducing the workload of repair crews. We shall consider the possibility of using the robotic diagnostic technology for overhead transmission lines.

\section{EXPERIENCE OF CREATING ROBOTIC DIAGNOSIS TECHNOLOGIES FOR OTL}

A number of digital technologies for fault diagnosis and localized repairs in overhead transmission lines is available in the world market.

Canada. The research institute of Canadian utility 'Hydro-Quebec' launched its robotics project LineScout in 1998 following an ice strom that took down power lines, leading to massive power outages and leaving millions of people without electricity for several days. The idea was to have a small mobile robot that could be able to roll on high-voltage transmission lines and de-ice them. The first line scout was a little rover that broke the ice. A later version of the robot was equipped with cameras and thermo-infrared sensors and could be used on energized high-voltage lines.

Today, the wheeled platform provides a thorough inspection of the components of overhead power lines, but has to be lifted by crane or helicopter, which means higher costs and limited real-time monitoring [28, 29].

Japan. Despite its reputation of being one of the most technologically advanced countries, Japan has areas where power lines have been in service for over 80 years. This makes the task of automated power line inspection and fault diagnosis highly relevant to Japan. In 2011, Tokyo-based company 'HiBot' in conjunction with the Kansai Electric Power Company presented the Expliner robot that is capable of inspecting bundled conductors [30].

For the robot to start operating, it needs to be hung on the wires. The robot is remotely controlled by an operator, who visually inspects the wires by getting a detailed feed from eight cameras that can deliver images of practically any section of the transmission line. In most cases, Expliner rolls like a train on rails, the difference being that it moves underneath the wires. Expliner has laser sensors to detect corrosion spots. The obtained data is transmitted via a GPRS channel. The robot is capable of getting around obstacles thanks to a shifted center of gravity.

Italy. Scientists at the RSE Research Laboratory in Milan have designed a robotic device (ILENA) for power line inspection and fault detection. The robot is made of stainless steel and aluminum and weighs $30 \mathrm{~kg}$ [31]. It has two mechanical arms, each with two motorized wheels, allowing it to slide across electric cables at a speed of 800 meters per hour. Thanks to four cameras and several sensors, it can transmit information back to operators on the ground. For now, the device is operated by remote control, but it will soon be completely autonomous.

It has to be noted that the robots described above (Fig. 2) need to be lifted and set up on de-energized overhead transmission lines by linemen.

Russia. In 2017, the Urals-based company Laboratoriya Budushchego (Future Lab) presented its Cablewalker project [32]. The device combines the latest trends in fault diagnosis in overhead 


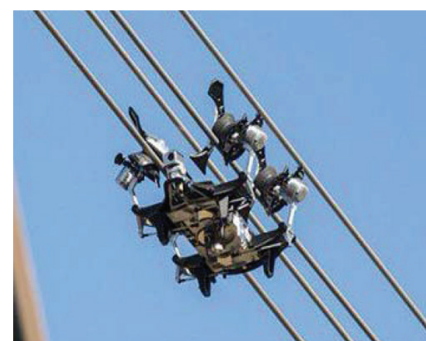

a)

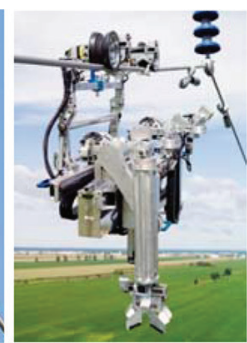

b)

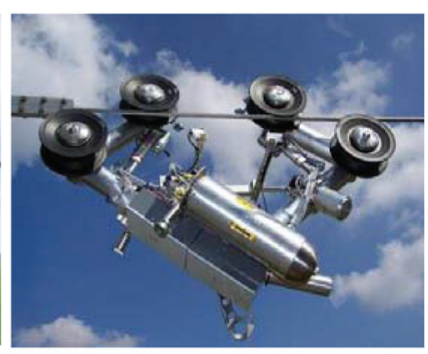

c)

Figure 2: Robots for fault diagnosis in overhead transmission lines:
a) LineRanger (Canada),
b) Expliner (Japan),
c) Ilena (Italy).

transmission lines and is a brand new technology for performing digital diagnosis, maintenance and localized repairs on components of the grid without de-energizing it. Cablewalker autonomously performs automated diagnostic activities from substation to substation.

The following components lie at the core of the Cablewalker operational concept.

1. A digital model of grids providing a high level of detail and registering all instrumentally measured elements of transmission lines, taking into account foreign objects in the buffer zone and building up essential statistics throughout the lifecycle of the diagnostic system.

2. A digital crew that performs maintenance and major repairs using completely new technical means and tools. The crew delivers the full range of activities that require the involvement of highly qualified personnel.

3. An unmanned mobile autonomous system that is controlled with a set of technical and software means performs the entire range of essential diagnostic, repair and maintenance works on components of grid facilities. The system consists of various types of robotic devices that are placed at hub substations.

4. An automatic data collection and processing system that analyzes data received from the diagnostic system, compares it to previous values, conducts time-based classification of deviations, predicts the approximate time of defect manifestation that could lead to a failure and builds a programme of corrective actions to address critical deviations in elements of transmission lines.

5. A server that stores, archives and provides access to grid condition data.

6. A digital dispatch service that monitors the condition of the grid on a real-time basis and remotely controls the entire fleet of robotic diagnostic and maintenance systems.

7. A blockchain platform that provides all potential market participants with nondiscriminatory access to up-to-date and accurate information about the technical condition of the grid and investments in fault diagnosis, maintenance and major repairs performed on the grid assets as a whole.

For now, the Cablewalker technology consists of several heavy and lightweight platforms that are designed for different kinds of missions and can be used for:

- researching and building a digital twin of the OTL;

- monitoring the grid and predict how deviations will develop in components;

- performing minor repairs on cables and conductors (application of liquid coating, tighten- 
Table 1: Specifications of Cablewalker platforms.

\begin{tabular}{|c|c|c|}
\hline & Spider (Pauk) & Dragonfly (Strekoza) \\
\hline Operation size & $1500 \times 1700 \times 650(\mathrm{~mm})$ & $1400 \times 1600 \times 700(\mathrm{~mm})$ \\
\hline Transportable size & $900 \times 900 \times 550$ & $700 \times 550 \times 550(\mathrm{~mm})$ \\
\hline Total mass & Up to $11 \mathrm{~kg}$ & Up to $11,5 \mathrm{~kg}$ \\
\hline Payload capacity & Up to $4 \mathrm{~kg}$ & Up to $4,5 \mathrm{~kg}$ \\
\hline Batteries & \multicolumn{2}{|c|}{$\begin{array}{l}\text { A pack of } 2 \text { batteries } \times 22,2 \mathrm{~V}, 16000 \mathrm{mAh} \text {, with an op- } \\
\text { tion to install two packs of batteries }\end{array}$} \\
\hline $\begin{array}{l}\text { GPS and GLONASS } \\
\text { sensitivity }\end{array}$ & \multicolumn{2}{|c|}{$160 \mathrm{~dB}$, positioning precision up to $2,5 \mathrm{~m}$} \\
\hline Communication interfaces & \multicolumn{2}{|c|}{ Radio, GPS and GLONASS, Wi-Fi } \\
\hline $\mathrm{Wi}-\mathrm{Fi}$ & \multicolumn{2}{|c|}{$\begin{array}{l}\text { Frequency bands } 2412-2462 \mathrm{MHz} \text {, signal power } 28 \mathrm{~dB} \text {, } \\
\text { signal range up to } 50 \mathrm{~km}\end{array}$} \\
\hline Radio transmitter & \multicolumn{2}{|c|}{$\begin{array}{l}\text { Frequency } 433 \mathrm{MHz} \text { FHSS, signal power } 500 \mathrm{~mW} \text {, signal } \\
\text { range up to } 1,5 \mathrm{~km}\end{array}$} \\
\hline Time of flight at $20^{\circ} \mathrm{C}$ & \multicolumn{2}{|l|}{ Up to $20 \mathrm{mins}$} \\
\hline $\begin{array}{l}\text { Maximum inspection dis- } \\
\text { tance }\end{array}$ & \multicolumn{2}{|l|}{ Up to $5 \mathrm{~km}$} \\
\hline Maximum takeoff angle & \multicolumn{2}{|l|}{ Up to $30^{\circ}$} \\
\hline Takeoff thrust & $15 \mathrm{~kg}$ & $16 \mathrm{~kg}$ \\
\hline Onboard computer & \multicolumn{2}{|l|}{ yes } \\
\hline Video camera & $\begin{array}{l}\text { Tarot Z30 Zoom 30x Full HD } \\
1920 \times 1080\end{array}$ & $\begin{array}{l}\text { Tarot Z30 Full HD } \\
1920 \times 1080\end{array}$ \\
\hline $\begin{array}{l}\text { Atmospheric pressure } \\
\text { requirements }\end{array}$ & \multicolumn{2}{|l|}{730 to $790 \mathrm{mmHg}$. } \\
\hline Humidity requirements & \multicolumn{2}{|l|}{45 to $95 \%$} \\
\hline Safe operating temperatures & \multicolumn{2}{|l|}{$-28^{\circ} \mathrm{C}$ to $+42^{\circ} \mathrm{C}$} \\
\hline $\begin{array}{l}\text { Maximum permissible wind } \\
\text { speed }\end{array}$ & \multicolumn{2}{|l|}{ Up to $10 \mathrm{M} / \mathrm{C}$} \\
\hline Stereo camera & ZED & - \\
\hline IR camera & - & $\begin{array}{l}\text { Tarot FLIR Vue Pro } 640 \\
\text { gimbal }\end{array}$ \\
\hline Laser scanner & - & $\begin{array}{l}\text { Hokuyo UTM-30LX with } \\
\text { a gimbal }\end{array}$ \\
\hline Magnetic scanner & - & Intros MB8-24 \\
\hline
\end{tabular}

ing of bolts, thermal imaging) with the use of robotic drones;

- installation and removal of diagnostic sensors on wires; automated creation of defect records; 
- engineering supervision over the construction and refurbishment of overhead transmission lines [32].

A project is under way aimed at making other technical tools compatible with the Cablewalker platform in order to considerably expand its repair and maintenance capabilities, enabling it to perform localized repairs on energized power lines; attachment and removal of fault indicators; installation of vibration dampers; tightening of bolted connections on conductors and cables; insulator washing; measuring the contact resistance in contact clamps and connectors; restoration of connection between the earth wire and the grounding rod.

The technical characteristics of some of the platforms that are included in Cablewalker are presented in Table 1.

It is worth noting that aour Russian and one international patents have been already issued for the Cablewalker system. Applications have been filed for patents in the USA, China, India, and the EU.

\section{TESTING AND EXPERIMENTAL RESULTS}

Field tests of the Cablewalker diagnostic robot have been conducted at various energy facilities across the world using different variants of its platforms (Table 2).

The most vivid example of the application of robot-assisted diagnosis was a field test of the Spider heavyweight platform that was conducted in August 2018. In the course of preparations for the diagnostic mission, a section of a power line was replicated in the simulator to define the phases of diagnostic tests and refining commands for the robot (Figs. 3 and 4). During the field trials, the system was tested for the capacity to perform diagnostic activities and the expediency of its application. For example, Fig. 5 shows a laser scanner and a stereo camera in operation.

Along with laser scanning, a magnetic scanner was tested in operation on the phase conductor. The test revealed hidden flaws of the steel core. The flaw image (Fig. 6) indicates that a decrease in the diameter of the core of the phase conductor results in the reduction of the

Table 2: Transmission lines for Cablewalker field tests.

\begin{tabular}{lll}
\hline Transmission line & Company, country & Year \\
\hline 220kV high voltage OTL SUGRES - Yuzhnaya & FGC UES, Russia & 2014 \\
500kV OTL Yuzhnaya - Tagil & FGC UES, Russia & 2014 \\
110kV OTL Ochakovo - Mazilovo & MOESK, Russia & 2015, \\
& & 2017 \\
110kV OTL Novo-Salavat CHP-Sibirskaya & Rosseti Ural, Russia & 2016 \\
220kV high voltage OTL Gumrak - Krasnoarmeyskaya & FGC UES, Russia & 2016 \\
35kV Polevskaya - Verkhnyaya Sysert & Rosseti Ural, Russia & $2017-$ \\
& & 2018 \\
Testing ground of Samara NIPI Neft & Rosneft, Russia & 2018 \\
DEWA testing ground, Dubai & DEWA, UEA & 2018 \\
220kV high voltage OTL EVN NPT & EVN NPT, Vietnam & 2018 \\
220kV high voltage OTL SUGRES - Ryabina & FGC UES, Russia & 2018 \\
\hline
\end{tabular}




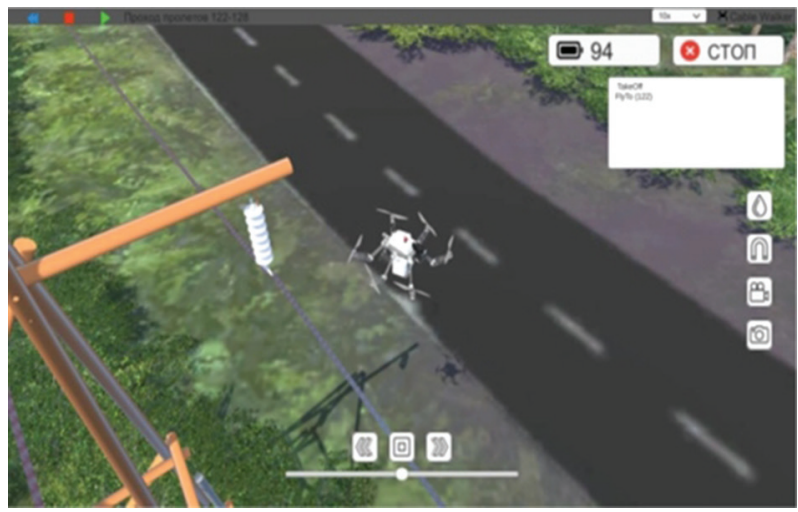

Figure 3: Simulation of platform flight and its landing on the line.

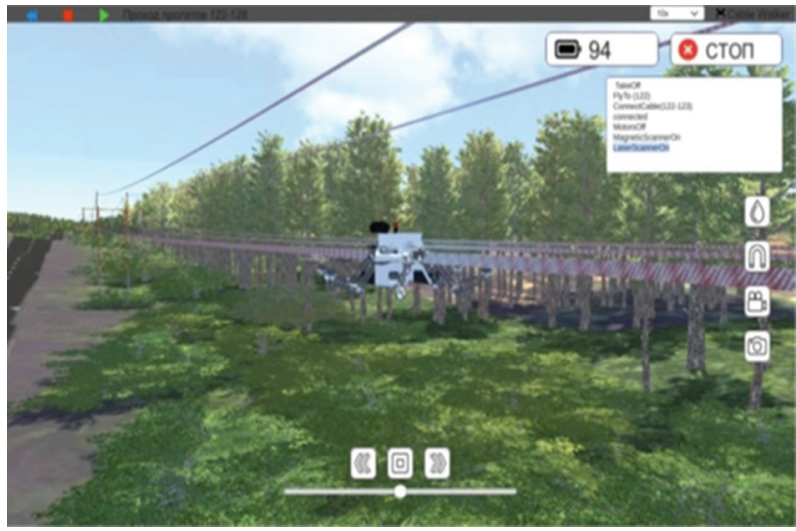

Figure 4: Simulation of platform movement along phase conductor.

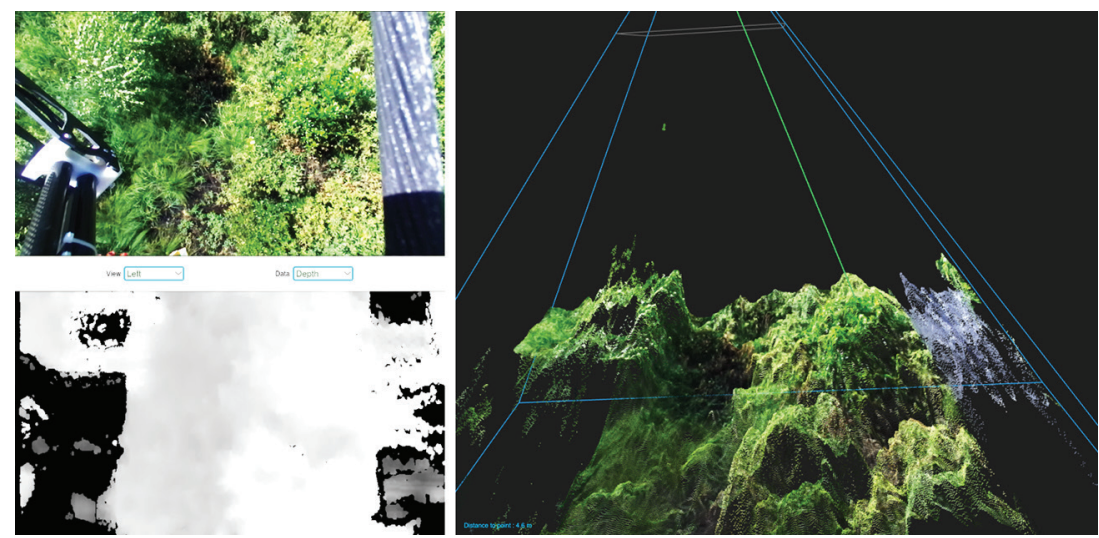

Figure 5: Visualization of laser scanner data. 


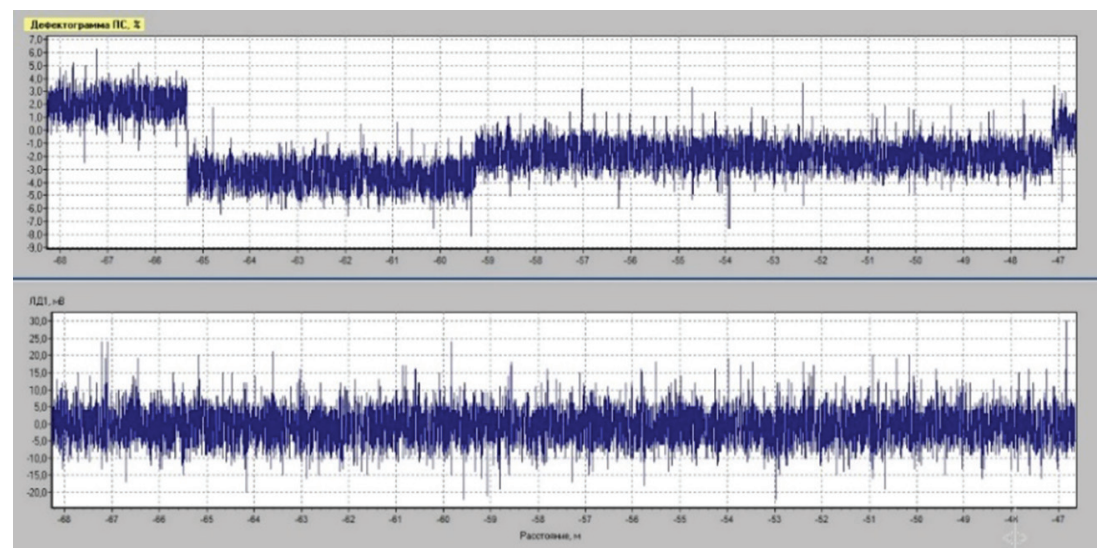

Figure 6: Conductor defect imaging.

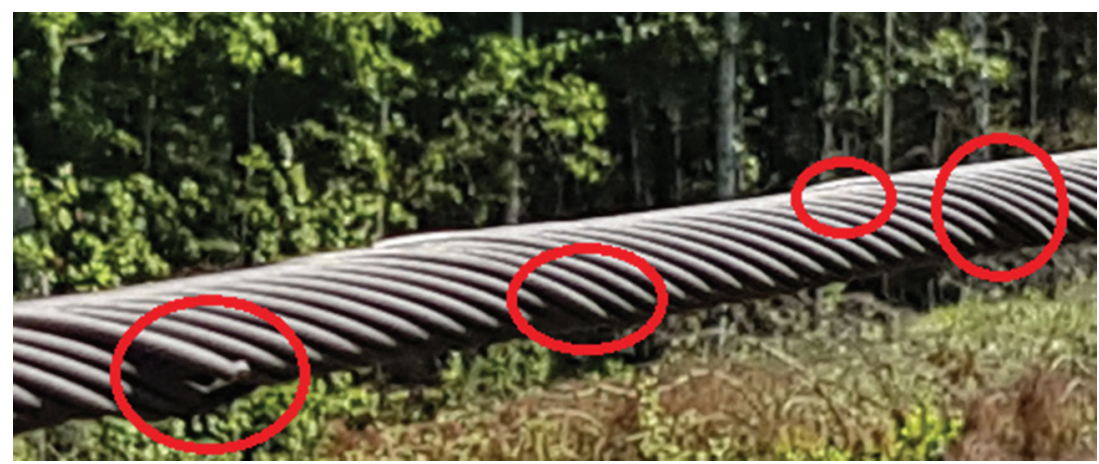

Figure 7: Broken wires in the top lay of the rope.

carrying capacity of the cable, which could lead to its rupture when exposed to low temperatures or gusts of wind or as a result of ice buildup on wires. When the Cablewalker platform with high-resolution cameras moves along the phase conductor, it inspects the upper side of the power line along the entire span to defect flaws that are not visible from the ground. An example of such flaws is depicted in Fig. 7. Also, the use of high-resolution cameras makes it possible to locate flaws not only in the wire, but also in accessories (for example, incorrect installation of vibration damper) and in elements of wood poles.

An inspection by Cablewalker of a 2.34-km-long section with 12 pylons revealed 112 issues and flaws that did not meet safety guidelines for overhead transmission lines. It has to be noted that linemen who had inspected the section had only registered three issues. The main causes of such low productivity of linesmen is the large number of hidden defects that cannot be detected visually from the ground; the shortage of powerful binoculors and lack of competence and motivation, which prevents workers from performing their duties diligently. Meanwhile, the platform, even when fitted with a limited set of special diagnostic devices, provided an objective picture of the actual condition of the OTL section and proved its advantage over manual inspections as part of the time-based preventive maintenance strategy. 
One of important deliverables of the Cablewalker technology is a digital model of the power line. The model contains up-to-date information about the technical condition of the equipment and makes it possible to manage it by taking into account various risks in various weather conditions. The latter feature is particularly relevant to Russia and other countries with challenging climates.

In order to calculate the cost effectiveness of the technology, three ten-year scenarios of power line overhaul and maintenance were developed in relation to the case of the Western Electric Grids branch of JSC Rosseti Ural, the largest grid company in Russia.

The first scenario simulated a complete overhaul and reconstruction of overhead transmission lines having voltages of 35 to $110 \mathrm{kV}$. A complete scheduled overhaul of the core equipment is the technologically most appropriate option that, however, entails the biggest expenditures. Considering the length $(1,600 \mathrm{~km})$ of the transmission lines operated by the branch and a high level of wear and tear $(40 \%)$, around 1 billion roubles ( 15.5 million dollars at the current exchange rate) would have to be allocated for the overhaul program annually.

A scenario based on a mixed maintenance approach (combining the time-based preventive and time-based diagnostic approaches) appears less costly and envisages gradual replacement of components of the core equipment (poles, insulators, conductors, grounding wires). Essentially, the scenario suggests that a part of the core equipment of each type of grid assets that has reached the end of its service life should be replaced in equal amounts year by year for a decade. The scenario has, however, proved inefficient due to the shortage of emergency response personnel in maintenance crews.

The third scenario is based on carrying out comprehensive robot-assisted diagnosis and replacing only those components that could cause defects in equipment and, as a result, a power line shutdown. In other words, the scenario implies condition-based major repairs. The focus is on all-encompassing instrumental diagnostic inspection of equipment and comprehensive analysis of the obtained information. Throughout the diagnostic process, the influence of the human factor that could distort the results is excluded.

To keep the experiment consistent, it is suggested that the robotic diagnosis project should, for the first year, be executed by a licensed firm operating under an outsourcing agreement.

Table 3: Comparison of various OTL refurbishment scenarios in application to Western Electric Grids branch of Rosseti Ural.

\begin{tabular}{|c|c|c|c|c|c|c|}
\hline & \multicolumn{2}{|c|}{ Scenario 1} & \multicolumn{2}{|c|}{ Scenario 2} & \multicolumn{2}{|c|}{ Scenario 3} \\
\hline & Year one & $\begin{array}{c}\text { Subsequent } \\
\text { years }\end{array}$ & Year one & $\begin{array}{c}\text { Subsequent } \\
\text { years }\end{array}$ & $\begin{array}{l}\text { Year } \\
\text { one }\end{array}$ & $\begin{array}{l}\text { Subsequent } \\
\text { years }\end{array}$ \\
\hline $\begin{array}{l}\text { Annual expen- } \\
\text { ditures, million } \\
\text { roubles }\end{array}$ & 1,084 & 1,083 & 268 & 268 & 158 & 111 \\
\hline $\begin{array}{l}\text { Method of } \\
\text { diagnosis }\end{array}$ & $\begin{array}{c}\text { By } \\
\text { linesmen }\end{array}$ & $\begin{array}{c}\text { By } \\
\text { linesmen }\end{array}$ & $\begin{array}{c}\text { By } \\
\text { linesmen }\end{array}$ & $\begin{array}{c}\text { By } \\
\text { linesmen }\end{array}$ & $\begin{array}{l}\text { Robotic } \\
\text { system }\end{array}$ & $\begin{array}{l}\text { Robotic } \\
\text { system }\end{array}$ \\
\hline Defects revealed & $10-30 \%$ & $10-30 \%$ & $10-30 \%$ & $10-30 \%$ & $90-98 \%$ & $90-98 \%$ \\
\hline $\begin{array}{l}\text { Reduction of } \\
\text { failure rate a } \\
\text { year }\end{array}$ & $10 \%$ & $30 \%$ & $20 \%$ & $40 \%$ & $50 \%$ & $90 \%$ \\
\hline
\end{tabular}


Table 4: Benefits of adopting robotic fault diagnosis technology.

\begin{tabular}{|c|c|c|}
\hline Technical & Organizational & Economic \\
\hline $\begin{array}{l}\text { Up-to-date graphic } \\
\text { representation of digital grid }\end{array}$ & $\begin{array}{l}\text { Possibility for continuous } \\
\text { diagnostic activities } \\
\text { throughout the year }\end{array}$ & $\begin{array}{l}\text { Reduction in operating } \\
\text { costs earmarked for OTL } \\
\text { fault diagnosis and effective } \\
\text { redistribution of expendi- } \\
\text { tures }\end{array}$ \\
\hline $\begin{array}{l}\text { Timely delivery of condition } \\
\text { on all elements of core } \\
\text { equipment }\end{array}$ & $\begin{array}{l}\text { Workplace injury and } \\
\text { fatalities completely ruled } \\
\text { out in the course of } \\
\text { diagnostic activities }\end{array}$ & $\begin{array}{l}\text { Savings of funds dedicated } \\
\text { to maintenance and OTL } \\
\text { refurbishment }\end{array}$ \\
\hline \multicolumn{2}{|c|}{$\begin{array}{l}\text { Diagnostic activities can be performed in hard-to access } \\
\text { areas regardless of time of year (marshes, extended rights } \\
\text { of way, mountainous regions, deep snow, floods) }\end{array}$} & $\begin{array}{l}\text { Reduction of costs of hav- } \\
\text { ing emergency response } \\
\text { crews; impact of seasonality } \\
\text { reduced to a minimum }\end{array}$ \\
\hline $\begin{array}{l}\text { Hidden OTL defects can be } \\
\text { detected with precision }\end{array}$ & \multicolumn{2}{|c|}{$\begin{array}{l}\text { Component replacement activities are scheduled on a } \\
\text { condition-based principle }\end{array}$} \\
\hline $\begin{array}{l}\text { Full compliance with } \\
\text { diagnostic schedule }\end{array}$ & \multicolumn{2}{|c|}{$\begin{array}{l}\text { Possibility of early prediction of defects and their timely } \\
\text { elimination }\end{array}$} \\
\hline \multicolumn{3}{|c|}{$\begin{array}{l}\text { Diagnostic activities are carried out without switching off the transmission line, which } \\
\text { means power supply is not disrupted }\end{array}$} \\
\hline
\end{tabular}

The budget of the project covers the creation of a 3D digital twin, entering the obtained results in SAP ERP, recording defects in an electronic logbook, planning of faulty component replacement works for the next reporting period. Comprehensive robot-assisted diagnostic examination will deliver a true-to-life picture of the technical condition of power lines. In subsequent years, the cost of the service will go down because there will be no need to build a 3D model. At the same time, the cost of repair and maintenance will be considerably reduced.

Table 3 presents a comparison of the scenarios over a ten-year horizon.

Of course, the initial costs of implementing the approaches described above are relatively high, but annual robotic-assisted diagnostic examinations will allow a reduction in the number of technical failures in transmission lines. The saved funds can be used for renovating outdated equipment. The application of the robotic diagnosis system for transmission lines has a number of benefits that make it possible to improve the reliability of power supply (Table 4).

\section{CONCLUSION}

The Cablewalker diagnostic system makes it possible to create a precise digital 3D model, or a digital twin, of a grid facility containing information about the condition of every key component. A digital twin allows effective management of grid assets, enabling the operator to obtain sufficient information about equipment with a voltage of $35 \mathrm{kV}$ and higher. A systemic approach to instrumental diagnosis makes it possible to detect up to $98 \%$ of defects. Only by practicing a comprehensive approach and comparing the obtained results with previous values of deviations registered in the digital twin can one predict how any defect will develop and how it can be 
tackled preemptively. The timely elimination of defects makes it possible to achieve a multifold reduction in the number of technological failures and improve the reliability of power supply.

The application of the robotic technology should be in line with a maintenance priority matrix that forms the basis of advanced grid asset management strategies. The authors believe that diagnostic examination should first be carried out on overhead power lines that had three or more shutdowns over the previous period. Transmission lines that deliver electricity to essential consumers come second in the line of priorities. As the third priority, diagnostic activities are performed on transit overhead power lines and other sections of power lines. Such ranking would help minimize the risk of failures, improve power supply reliability and reduce non-delivery of electricity to consumers.

Pilot trials of the Cablewalker technology showed that the biggest share of the technology adoption costs is generated by primarily diagnostic activities that are linked to the creation of a digital twin. Analyzing the obtained results over a period of time, it is possible to program variation in component parameters and compare them to standard values, thus predicting the development of the defect and time of its occurrence. The method makes it possible to preemptively reveal bottlenecks and eliminate defects in key components prior to an emergency shutdown of the overhead power line. In the long run, it would enable more effective decision making as to the refurbishment/replacement of components considering their technical condition and reliability. This would help reduce SAIDI/SAIFI, make energy companies more attractive to investors and improve the quality of power supply to end users.

\section{ACKNOWLEDGEMENTS}

The work was supported by Act 211 of the Government of the Russian Federation, contract № 02.A03.21.0006.

\section{REFERENCES}

[1] Digital Transformation of Industries. Electricity Industry. World Economic Forum White Paper, 2016, https://www.accenture.com/_acnmedia/Accenture/ConversionAssets/WEF/PDF/Accenture-Electricity-Industry.pdf (accessed 04 June 2019).

[2] The Digital Energy Transformation, https://www.ge.com/content/dam/gepower-pw/ global/en_US/documents/hybrid/des/GE_Digital_Transformation.PDF (accessed 04 June 2019).

[3] Butler, C., Parkhill, K.A. \& Luzecka, P., Rethinking energy demand governance: Exploring impact beyond 'energy' policy. Technological Energy Research \& Social Science, 36, pp. 70-78, 2018. https://doi.org/10.1016/j.erss.2017.11.011

[4] Chebotareva, G.S., Impact of state support mechanisms on the cost of renewable energy projects: The case of developing countries. WIT Transactions on Ecology and the Environment, 217, pp. 881-891, 2018. https://doi.org/10.2495/sdp180741

[5] Goldbach, K., Rotaru, A.M., Reichert, S., Stiff, G. \& Gölz, S., Which digital energy services improve energy efficiency? A multi-criteria investigation with European experts, Energy Policy, 115, pp. 239-248, 2018. https://doi.org/10.1016/j.enpol.2017.12.036

[6] Morley, J., Widdicks, K. \& Hazas, M., Digitalisation, energy and data demand: The impact of Internet traffic on overall and peak electricity consumption. Energy Research \& Social Science, 38, pp. 128-137, 2018. https://doi.org/10.1016/j.erss.2018.01.018

[7] Baev, I., Dzyuba, A., Solovyeva, I. \& Kuzmina, N., Improving the efficiency of using small-distributed generation systems through mechanisms of demand management for electricity and gas. International Journal of Energy Production and Management, 3(4), pp. 277-291, 2018. https://doi.org/10.2495/eq-v3-n4-277-291 
[8] Wissner, M., The Smart Grid - A saucerful of secrets? Applied Energy, 88(7), pp. 2509-2518, 2011. https://doi.org/10.1016/j.apenergy.2011.01.042

[9] Johnstone, P. \& Kivimaa, P., Multiple dimensions of disruption, energy transitions and industrial policy. Energy Research \& Social Science, 37, pp. 260-265, 2018. https://doi. org/10.1016/j.erss.2017.10.027

[10] Gitelman, L., Magaril, E., Kozhevnikov, M. \& Rada, E.C., Rational Behavior of an Enterprise in the Energy Market in a Circular Economy, Resources, 8(2), p. 73, 2019. https://doi.org/10.3390/resources 8020073

[11] Larsen, P.H., A method to estimate the costs and benefits of undergrounding electricity transmission and distribution lines. Energy Economics, 60, pp. 47-61, 2016. https://doi. org/10.1016/j.eneco.2016.09.011

[12] Xie, Y., Li, C., Lv, Y. \& Yu, C., Predicting lightning outages of transmission lines using generalized regression neural network. Applied Soft Computing, 78, pp. 438-446, 2019. https://doi.org/10.1016/j.asoc.2018.09.042

[13] Kishore, T.S. \& Singal, S.K., Optimal economic planning of power transmission lines: A review. Renewable and Sustainable Energy Reviews, 39, pp. 949-974. https://doi. org/10.1016/j.asoc.2018.09.042

[14] Mesić, M. \& Plavšić, T., The contribution of failure analyses to transmission network maintenance preferentials. Engineering Failure Analysis, 35, pp. 262-271, 2013. https://doi.org/10.1016/j.engfailanal.2013.01.028

[15] Meenakshi Devi, M., Geethanjali, M. \& Rama Devi, A., Fault localization for transmission lines with optimal Phasor Measurement Units. Computers \& Electrical Engineering, 70, pp. 163-178, 2018. https://doi.org/10.1016/j.compeleceng.2018.01.043

[16] Menéndez, O., Pérez, M. \& Cheein, F.A., Visual-Based Positioning of Aerial Maintenance Platforms on Overhead Transmission Lines, Applied Sciences, 9(1), p. 165, 2019. https://doi.org/10.3390/app9010165

[17] da Silva, P.R.N., Negrão, M.M.L.C., Vieira Junior, P. \& Sanz-Bobi, M.A., A new methodology of fault location for predictive maintenance of transmission lines. International Journal of Electrical Power \& Energy Systems, 42(1), pp. 568-574, 2012. https://doi. org/10.1016/j.ijepes.2012.04.057

[18] Ferreira, E.F. \& Barros, J.D., Faults monitoring system in the electric power grid of medium voltage. Procedia Computer Science, 130, pp. 696-703, 2018. https://doi. org/10.1016/j.procs.2018.04.123

[19] Samadi, M., Seifi, H. \& Haghifam, M.R., Midterm system level maintenance scheduling of transmission equipment using inspection based model. International Journal of Electrical Power \& Energy Systems, 110, pp. 467-476, 2019. https://doi.org/10.1016/j. ijepes.2019.03.050

[20] Nagarajan, B., Li, Y., Sun, Z. \& Qin, R., A routing algorithm for inspecting grid transmission system using suspended robot: Enhancing cost-effective and energy efficient infrastructure maintenance. Journal of Cleaner Production, 219, pp. 622-638, 2019. https://doi.org/10.1016/j.jclepro.2019.02.088

[21] Daim, T.U., Yoon, B.S., Lindenberg, J., Grizzi, R., Estep, J. \& Oliver, T., Strategic roadmapping of robotics technologies for the power industry: A multicriteria technology assessment. Technological Forecasting and Social Change, 131, pp. 49-66, 2018. https://doi.org/doi: 10.1016/j.techfore.2017.06.006

[22] Tavares, L. \& Sequeira, J.S., RIOL - Robotic Inspection Over Power Lines, IFAC Proceedings Volumes, 40(15), pp. 108-113, 2007. https://doi.org/10.3182/200709033-FR-2921.00021 
[23] Ben-Daya, M., Duffuaa, S., Raouf, A., Knezevic, J. \& Ait-Kadi, I., Handbook of Maintenance Management and Engineering, London: Springer-Verlag, p. 746, 2009.

[24] Schneider J., Gaul A., Neumann C., Hogräfer J., Wellbow W., Schwan M. \& Schnettlek A., Asset management techniques. International Journal of Electrical Power \& Energy Systems, 28(9), pp. 643-654, 2006. https://doi.org/10.1016/j.ijepes.2006.03.007

[25] Hoff, G. \& Kranz, H.G., Condition based maintenance of PE/XLPE-insulated medium voltage cable networks-verification of the IRC-analysis to determine the cable age. Conference Record of the 2002 IEEE International Symposium on Electrical Insulation, 2002. https://doi.org/10.1109/ELINSL.2002.995879

[26] de la Fuente, A., González-Prida, V., Crespo, A., Gómez, J.F. \& Guillén, A., Advanced Techniques for Assets Maintenance Management. IFAC-PapersOnLine, 51(11), pp. 205-210, 2018. https://doi.org/10.1016/j.ifacol.2018.08.260

[27] Heo, J.H., Kim, M.K. \& Lyu, J.K., Implementation of Reliability-Centered Maintenance for transmission components using Particle Swarm Optimization. International Journal of Electrical Power \& Energy Systems, 55, pp. 238-245, 2014. https://doi. org/10.1016/j.ijepes.2013.09.005

[28] Aracil, R., Pinto, E. \& Ferre, M., Robots for live-power lines: maintenance and inspection tasks. IFAC Proceedings Volumes, 35(1), pp. 13-18, 2002. https://doi. org/10.3182/20020721-6-ES-1901.00814

[29] LineScout, A robot for inspecting live transmission lines, http://www.hydroquebec. com/innovation/en/pdf/2010G080-02A_LineScout.pdf (accessed 04 June 2019).

[30] EXPLINER-Inspection Robot for High-Voltage Transmission Lines, https://www. jsme.or.jp/jsme/uploads/2016/11/awardu12-4.pdf (accessed 04 June 2019).

[31] Project T\&D 2014. Transmission and distribution of the electric energy, http://www2. rse-web.it/progetti/progetto/649 (accessed 04 June 2019).

[32] CABLEWALKER official website, http://cablewalker.com/en/ (accessed 04 June 2019). 